\title{
An Electrochemical Microactuator: Principle and First Results
}

\author{
Cristina R. Neagu, Johannes G. E. Gardeniers, Miko Elwenspoek, and John J. Kelly
}

\begin{abstract}
A novel electrochemical microactuator made with the use of silicon micromachining techniques, and its feasibility, are presented. Gas pressure is generated by electrolysis of an aqueous electrolyte solution. The pressure built up is used to change the deflection of a membrane. The actuator has three states: the electrolysis state, in which the pressure is built up; the passive state, in which the circuit is open and the pressure is maintained; and the pressure reduction state, in which the electrodes are short-circuited in order to reverse the electrolysis reaction. The advantage of this type of actuation is a relatively large pressure generation with low energy consumption. Power is required only for pressure build-up and for changing the states. Therefore, this type of actuation has promising applications in pumps or active valves. [162]
\end{abstract}

\section{INTRODUCTION}

T HE use of silicon microtechnology has increased rapidly during the last years. Based on this technology, there is a growing interest in research on microliquid handling systems [1]. Basic components such as pumps, passive/active valves, and flow sensors have already been realized using different principles such as electrostatic, piezoelectric, or thermopneumatic [2], [3].

A relatively new principle is electrochemical actuation, which is based on the electrolysis of an aqueous electrolyte solution. The reversible chemical reactions, which are driven by an external current/voltage source, lead to gas evolution. In a closed system, the generation of gas pressure can be used to change the deflection of a membrane (Fig. 1). The chemical reaction can be reversed by short-circuiting the electrodes or by reversing the polarity of the externally applied supply. As a result, the pressure obtained is reduced and the deflection of the membrane decreases. Under open-circuit conditions, the pressure in the actuator will in principle be maintained, as well as the deflection state of the membrane. This means that no energy is required to keep this state, in contrast to conventional actuation principles. Relatively large pressures can be created, and therefore the actuator is attractive for use in microliquid handling systems such as pumps or active valves (see Fig. 2, for example).

Electrochemical actuators were reported for the first time by Janocha [4] and Kempe [5]. These devices, with a size

Manuscript received July 7, 1995; revised November 30, 1995. Subject Editor, N. de Rooij. This work was supported by the Netherlands Technology Division (STW).

C. R. Neagu, J. G. E. Gardeniers, and M. Elwenspoek are with Mesa Research Institute, University of Twente, $7500 \mathrm{AE}$ Enschede, The Netherlands

J. J. Kelly is with the Debye Institute, University of Utrecht, 3508 TA Utrecht, The Netherlands.

Publisher Item Identifier S 1057-7157(96)02253-6.

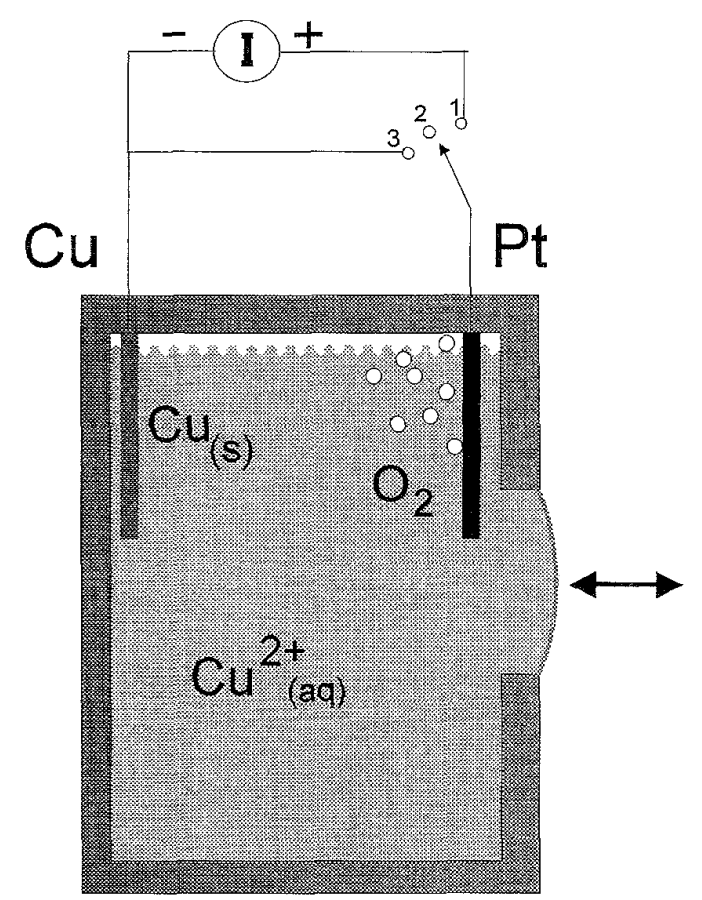

Fig. 1. Schematic representation of the electrochemical actuation. The cell consists of two electrodes (copper and platinum) and copper sulphate electrolyte inside a closed cavity where oxygen gas pressure is generated.

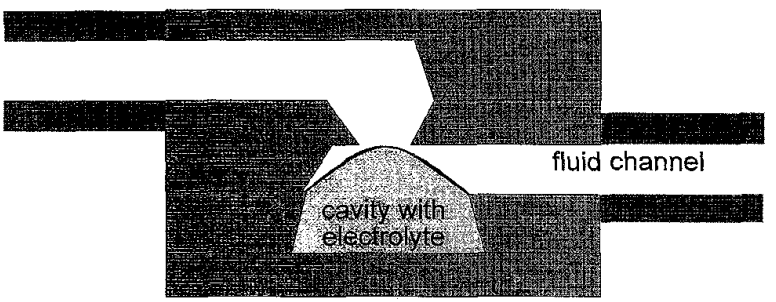

Fig. 2. Possible design for an active valve with the help of electrochemical actuation. By adjusting the deflection of the membrane, flow resistance can be controlled.

of a few cubic centimetres, were made with the use of conventional techniques by assembling stainless steel parts. Design, technological process, and preliminary results of a new electrochemical actuator based on micromechanical fabrication techniques were presented for the first time in [6]. In this paper, an insight into the working principle and some first performance results are described. 


\section{PRINCIPLE}

\section{A. Electrochemical Reactions}

Depending on requirements and applications, several electrochemical reactions can be chosen [7] and the actuator can be operated with different results. The choice of the electrodes and ions in the solution determines the kind of gas that evolves at the electrode(s). The build-up time of the pressure depends on different variables that affect the electroded reaction rate [8]: electrode material, surface area, volume, geometry, surface condition; ionic and gas diffusion, convection; electrolyte concentration (some oxygen will dissolve in water depending on the pressure of the oxygen); external effects (temperature, pressure); and finally, electrical parameters (current density, overpotential, impedance).

The experiment can be performed either by controlling the current externally and measuring the resulting changes in potential at the working electrode or by controlling the potential and measuring the resulting current [8], [9], [12]. Under controlled potential conditions (potentiostatical), the potential of the electrode with respect to a reference can be set at a value that ensures that only one chemical process can take place. The surface concentration is held constant and the mass flux (the current density is proportional to it) related to the specific rate constant of the reaction decreases with time. The measurements at constant current (galvanostatical) have the rate of the reaction controlled externally, and thus the gradient of concentration (flux) of reactant at the electrode surface is constant (but the surface concentration decreases with time). Since the current is constant, the rate of product generation can be calculated without any specification of the rate constant of the reaction. The choice between these methods depends on the application.

The measurements described below are conducted at constant current. In this way, the number of moles of gas formed can be calculated, and the gas pressure may be estimated. The current flowing in the cell is stepped from zero to a finite value, and the potential of the cell is measured as a function of time (chronopotentiometry) [9].

When a current step is applied, three processes take place: the ionic double layer (between electrode and electrolyte) charges up, the charge-transfer reaction starts (causing the activation overpotential to reach its steady-state value), and concentration gradients are set up near the electrode surface, giving rise to concentration polarization and causing a further increase of overpotential. Charging of the double layer is a relatively fast process (about $10 \mu \mathrm{s}$ ) and therefore should not interfere with the measurements. When the current pulse has a long duration [8], [10], mass transport by convection occurs, and the competing reactions give a complex response of the interphase, which is often difficult to study.

Reversibility is an important attribute of the actuator, and therefore chemical reactions should be reversible. The chosen electrolyte has to be compatible with forward/back reactions at both electrodes. We chose only one type of gas evolution, oxygen, a solution of copper sulphate, and platinum $(\mathrm{Pt})$ and copper $(\mathrm{Cu})$ electrodes. The platinum electrode acts as a catalyst for the formation of oxygen gas.

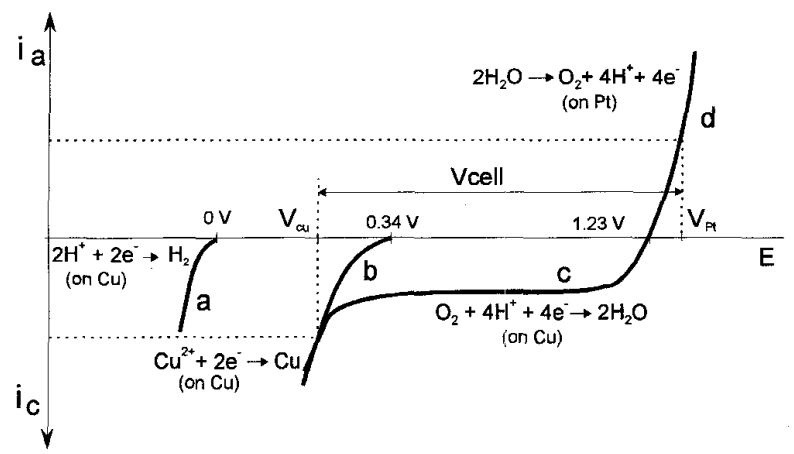

Fig. 3. Qualitative description of partial anodic and cathodic current, $i_{a}$ and $i_{e}$, as a function of potential (vs. NHE) during electrolysis at a copper electrode: hydrogen evolution (curve a), copper deposition (curve b), oxygen reduction (curve c); and at the platinum electrode: oxygen evolution (curve d).

Depending on the direction in which the chemical reaction proceeds, three states of the actuator are distinguished.

Electrolysis State: During electrolysis, water dissociates and oxygen gas evolves at the anode $(\mathrm{Pt})$

$$
2 \mathrm{H}_{2} \mathrm{O}_{(\mathrm{l})} \Rightarrow \mathrm{O}_{2(\mathrm{~g})}+4 \mathrm{H}^{+}(\mathrm{aq})+4 \mathrm{e}^{-}
$$

with standard, equilibrium potential $E^{0}=1.23 \mathrm{~V}$, while copper ions precipitate at the cathode $(\mathrm{Cu})$

$$
\mathrm{Cu}^{2+}{ }_{(\mathrm{aq})}+2 \mathrm{e}^{-} \Rightarrow \mathrm{Cu}_{(\mathrm{s})}
$$

with $E^{0}=0.34 \mathrm{~V}$.

The overall cell reaction for $\mathrm{O}_{2(\mathrm{~g})}$ production is

$$
2 \mathrm{H}_{2} \mathrm{O}_{(\mathrm{l})}+2 \mathrm{Cu}^{2+}{ }_{(\mathrm{aq})} \Leftrightarrow \mathrm{O}_{2(\mathrm{~g})}+4 \mathrm{H}^{+}{ }_{(\mathrm{aq})}+2 \mathrm{Cu}_{(\mathrm{s})}
$$

with $E^{0}=0.89 \mathrm{~V}$.

The dependence of partial anodic and cathodic currents on potential at both copper and platinum electrodes is shown schematically in Fig. 3. The total current passing through the circuit is the sum of all partial currents. The evolution of oxygen gas is represented by line $\mathrm{d}$, and the deposition of copper by line $b$.

If the voltage across the cell has a value higher than that necessary for $\mathrm{H}^{+}$ion reduction, hydrogen evolution might occur at the copper electrode (line a of Fig. 3)

$$
2 \mathrm{H}^{+}(\mathrm{aq})+2 \mathrm{e} \Rightarrow \mathrm{H}_{2(\mathrm{~g})} \text {. }
$$

The evolution of hydrogen has a negative effect on the adhesion of $\mathrm{Cu}$ during its deposition and therefore causes a shortening of the lifetime of the electrode. This reaction depends primarily on the nature of the metal used as electrode [11], e.g., on copper the exchange current density for reduction of hydrogen ions is about 200 times lower than on platinum [12].

The presence of oxygen dissolved in the electrolyte causes another parasitic reaction at the copper electrode. The reduction of oxygen to water (the reverse of reaction 1) takes place because its equilibrium potential is more positive than that for copper deposition (line $\mathrm{c}$ of Fig. 3). The solubility of oxygen 
in water is low, and the limiting diffusion current for oxygen is reached quickly (the reduction of oxygen is diffusion limited). This unwanted reaction decreases the oxygen gas pressure and therefore the efficiency of the actuator. To reduce this effect, the copper electrode has to be protected against oxygen, using, e.g., an ion-exchange polymer membrane Nafion(8) [13]. Nafion $B$ is permeable to many positive ions, so that the current loop during electrolysis is closed [14], and for polar compounds, but it is impermeable to negative ions and nonpolar compounds such as oxygen gas. It is known [15] that the permeability of oxygen through a Nafion membrane in the dry state is much lower than in the wet state, and therefore the gas permeation is closely related to water uptake of the membrane, and directly affects the mass transfer rate of gases to the electrode.

During electrolysis gas bubbles are generated through the following general steps: initially, electrolytically developed gas dissolves into the electrolyte. Low solubility in liquid and small diffusion coefficients of the gas will lead to supersaturation of the electrolyte in the vicinity of the electrode. At very low current densities the dissolved gas will be transported to the bulk by means of diffusion and (natural) convection. As a consequence, a stationary state will be reached: the supersaturation at the electrode surface will become constant in time. At higher current densities the supersaturation at the electrode surface will increase and will exceed a value necessary for the formation of gas bubbles. Finally, the detachment of gas bubbles occurs when the Archimedes' force on the bubble overcomes the surface forces of adhesion.

The performance of the electrochemical cell might be affected by generated gas bubbles in two ways [16], [17]: 1) the resistance of the gas-liquid electrolyte mixture increases at higher gas production rates, and 2) the mass transfer to and from electrodes of the ions and the gas varies in time.

Passive State: Under open circuit conditions, the pressure built up is maintained, but this "steady state" can be disturbed by leakage from the system or by parasitic reactions at the copper electrode. These parasitic reactions are presented qualitatively in Fig. 4. The dissolution (oxidation) of copper (line b of Fig. 4), which is equivalent to corrosion, cannot proceed unless another process takes place at the same rate to carry away the electrons accumulated in the metal. The cathodic reactions that are coupled with this anodic dissolution in aqueous solution are usually hydrogen evolution and/or reduction of oxygen dissolved (lines a and $b$, respectively). The corrosion potential is determined by both thermodynamic (reversible potentials of the two processes taking place) and kinetic factors (exchange-current densitites). The direction of spontaneous reactions and the thermodynamically most stable corrosion products will depend on the standard reduction potential of copper ions, oxygen, and water, and on the $\mathrm{pH}$, oxygen partial pressure, and temperature [11]. If the corrosion products of copper are insoluble and precipitate on the electrode, nonuniform surface conditions are introduced and the electrical characteristics of the electrode/cell and the kinetics of reactions are affected. Copper cannot be oxidized by hydrogen ions (reaction 4 is not energetically favorable: $\left.\Delta E^{0}=-0.34 \mathrm{~V}\right)$, but the oxygen dissolved can be reduced

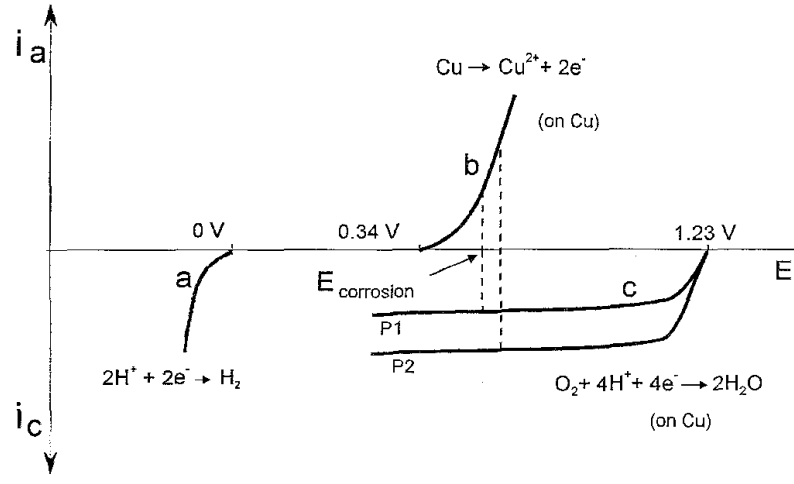

Fig. 4. Schematic current-potential relationship for parasitic reactions that may occur at the copper electrode during the passive state: hydrogen evolution (curve a), copper dissolution (curve b), and oxygen reduction (curve c) for two concentrations of oxygen dissolved $(\mathrm{P} 1<\mathrm{P} 2)$. The corrosion potential mainly depends on the concentration of oxygen dissolved.

on the copper surface. The higher the amount of oxygen dissolved, the faster the corrosion of copper (see line $\mathrm{c}$ of Fig. 4), and because of that the oxygen pressure decreases.

Pressure Reduction State: This can be achieved by externally short-circuiting the cell or by reversing the polarity. In the reverse reaction, generated oxygen is reduced to water and solid copper is oxidized to copper ions. The partial currents of these reactions are shown qualitatively in Fig. 5. The reduction of oxygen by short-circuiting the cell, shown in Fig. 5(a), occurs at both electrodes, and copper is oxidized at copper electrode. Reversing the polarity, oxygen and copper ions are reduced at the platinum electrode and solid copper is oxidized to copper ions at the copper electrode, as shown in Fig. 5(b).

Depending on the nature of the electrode, the composition and purity of the solution, and the range of potential studied, oxygen can be reduced either to hydrogen peroxide (two consecutive two-electron steps) or to water (a direct fourelectron step) [17], [18]. Therefore, the occurrence of several simultaneous electrochemical reactions at the surface of the electrode makes the studies of electrode kinetics, and of overall cell behavior, very complex. An exact relationship is very difficult to establish and the experimental data difficult to interpret.

\section{B. Membrane Deflection-Pressure Relationship}

The good performance of membranes is important for the success of the micromechanical actuators. As active valves and pumps, for example, membranes capable of large deflection can be used to transform pressure into displacement. The relationship between deflection of the membrane and pressure is important to know in order to characterize the behavior of the actuator. The effect of applied pressure on membrane deflection was modelled using the theory for small and large deflections of flat and corrugated membranes [19], [20]. For small deflections, the relationship between pressure and deflection is linear (only bending of the membrane occurs). The nonlinearity that occurs with large deflections is the result of tensile stress caused by the stretching of the membrane. If large initial stress is present in the membrane, due to deposition 


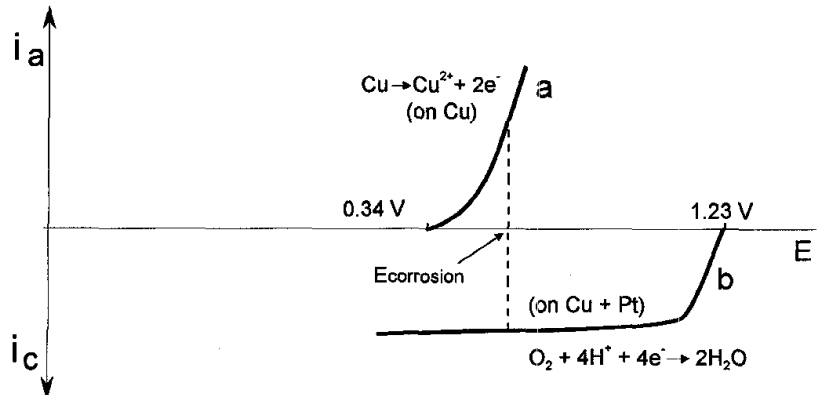

(a)

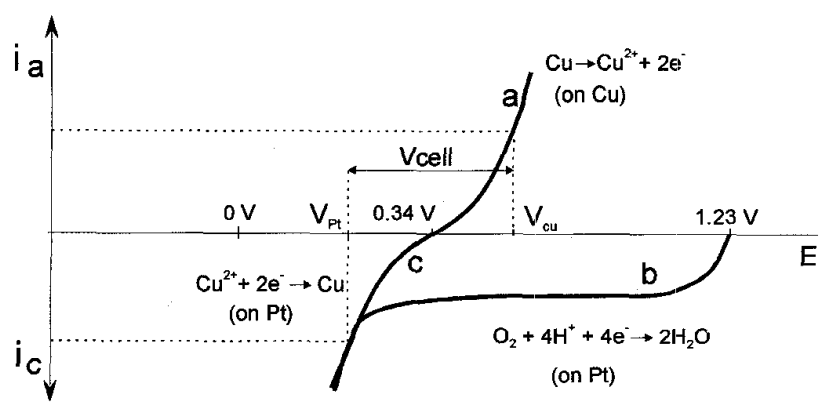

(b)

Fig. 5. Schematic current-potential relationship during pressure reduction state. (a) short-circuit conditions: copper oxidation at copper electrode (curve a), oxygen reduction at both electrodes (curve b); (b) reversed polarity conditions: copper oxidation at copper electrode (curve a), copper ions reduction at platinum electrode (curve $\mathrm{c}$ ), and oxygen reduction at platinum electrode (curve b).

process parameters and packaging, the effect of bending can be ignored, and a new first-order term is introduced [21].

For a flat, square membrane of thickness $h$, length $2 a$, Young's modulus $E$, Poisson's ratio $v$, and initial stress $\sigma$, the relationship between the pressure difference $P$ over the membrane and the corresponding center deflection $y$ is described by [22]

$$
P=\frac{3.41 \sigma h}{a^{2}} \cdot y+\frac{E h}{a^{4}} \cdot \frac{1.98 \cdot(1-0.295 v)}{1-v} \cdot y^{3} .
$$

The introduction of corrugations in the membrane increases the cross-sectional length of the membrane and greatly increases the deflection range. For corrugated membranes the pressuredeflection formulas are [20]

$$
P=\frac{E h^{3}}{a^{4}} A \cdot y+\frac{E h}{a^{4}} B \cdot y^{3}
$$

where $A=\frac{2(3+q)(1+q)}{3\left(1-\frac{v^{2}}{q^{2}}\right)}, B=\frac{32}{q^{2}-9}\left[\frac{1}{6}-\frac{3-v}{(q-v)(q+3)}\right]$, the profile factor $q^{2}=\frac{s}{l}\left[1+1.5 \frac{H^{2}}{h^{2}}\right], s$ is the corrugation profile, $l$ is the corrugation frequency, and $H$ is the corrugation depth. As the number and frequency of corrugations increase, deflection increases, indicating an increase in mechanical sensitivity of the membrane (for membranes with initial internal stress). The presence of corrugations reduces initial stress [23], and for large corrugation depths the mechanical sensitivity of the membrane only weakly depends on initial

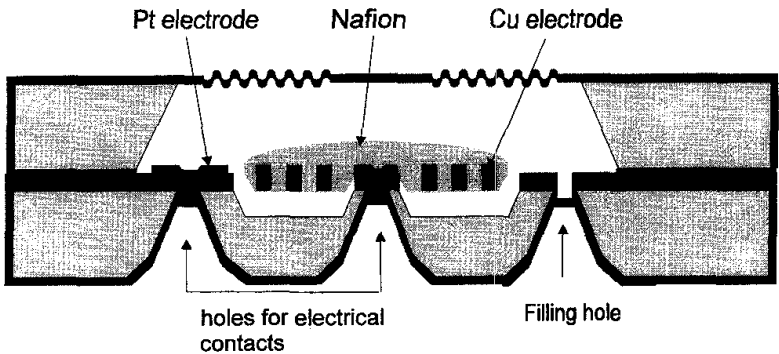

(a)

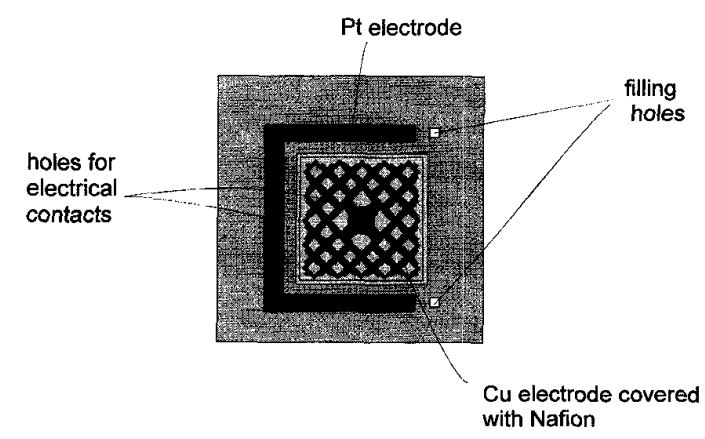

(b)

Fig. 6. Schematic design of the micromachines electrochemical actuator. The area of the platinum electrode is $1.5 \mathrm{~mm}^{2}$, that of the copper electrode is about $0.8 \mathrm{~mm}^{2}$, and the volume of the cell cavity is around $1.3 \mathrm{~mm}^{3}$. (a) Side view. (b) Top view.

stress. The effects of internal stress cannot be treated as easily as for planar diaphragms, where a simple term is added to the pressure-deflection equation. Therefore, analytical analysis [24] or a finite-element method become necessary in modeling the effects of different corrugation profiles and membrane thickness on pressure-deflection characteristics.

\section{EXPERIMENT}

The microactuator has been made with the use of silicon micromachining and thin film techniques. The actuator is realized by using two processed silicon wafers and consists of two main parts [6]: the electrochemical cell and the deflecting membrane, which is used for pressure-to-deflection transformation, both shown schematically in Fig. 6 . The electrochemical cell uses two electrodes, $\mathrm{Pt}$ and $\mathrm{Cu}$. A layer of $1-\mu \mathrm{m}$ silicon nitride $\left(\mathrm{Si}_{3} \mathrm{~N}_{4}\right)$ deposited by low pressure chemical vapor deposition (LPCVD) on the silicon wafer acts as electrical insulator between the electrodes and the silicon substrate. The planar electrodes are patterned by lift-off; $1 \mu \mathrm{m}$ of $\mathrm{Cu}$, and $0.5 \mu \mathrm{m}$ of $\mathrm{Pt}$ are deposited by dc magnetron sputtering, with $20 \mathrm{~nm}$ $\mathrm{Ti}$ as the adhesion layer.

The deflecting membranes are made of $1-\mu$ m-thick lowstress LPCVD silicon nitride, and the fabrication process of corrugated membranes consists basically of three steps: 1) frontside etching of corrugations in the silicon wafer by reactive ion etching (RIE) in an $\mathrm{SF}_{6} / \mathrm{O}_{2} / \mathrm{CHF}_{3}$ plasma, 2) deposition of 1- $\mu \mathrm{m}$ low-stress LPCVD silicon nitride on both sides of the wafer, and 3) backside etching of the silicon wafer in $\mathrm{KOH}$ solution. 
TABLE $\Upsilon$

Experimental Data for the Gas leakage Rate of Some Types of Glue

\begin{tabular}{l|c}
\hline \multicolumn{1}{c|}{ Glue } & leakage rate $[\mathrm{mbar} \cdot \mathrm{l} / \mathrm{s}]$ \\
\hline Adolf Würth GmbH \& Co. KG & $2.2 \times 10^{-8}$ \\
\hline Araldit Ciba-Geigy B.V. & $4.7 \times 10^{-9}$ \\
\hline High Super 5 Semedain Co.Ltd. & $4 \times 10^{-9}$ \\
\hline Silastic Dow Corning GmbH & $3.1 \times 10^{-8}$ \\
\hline Hysol Dexter Electronic & $5 \times 10^{-9}$ \\
\hline
\end{tabular}

The $\mathrm{Cu}$ electrode was protected against oxygen gas with a layer of Nafion $\AA$ (gel). The major problem of using $N a f i o n \AA$ in micromechanical applications is its bad adhesion. The $\mathrm{Cu}$ electrode is constructed as a perforated standing table as an attempt to solve this problem. The Nafion $B$ gel is made by applying the Nafion $\left({ }^{B}\right.$ solution onto the $\mathrm{Cu}$ grid and slowly evaporating the alcohol solvent.

The holes for filling the cavity and those for electrical contacts, which are on the backside of the wafer, are made by $\mathrm{KOH}$ etching. The volume of the cell cavity is about 1.3 $\mathrm{mm}^{3}$. In principle the two processed wafers can be bonded at $300^{\circ} \mathrm{C}$ to form a sealed cavity; however, at this temperature the properties of Nafion ${ }^{\circledR}$ change. Therefore, for the tests presented here, the bonding and the closing of the filling holes were done at toom temeprature with "High Super 5" a Japanese double compound (epoxy), which was found to be the most suitable for this purpose. Different types of commercial glues were tested for gas leakage in the following way. A sample filled with helium and sealed with the glue to be tested was placed in a vacuum chamber and the helium leakage rate was measured. The background leakage rate of helium measured in the vacuum chamber without sample was $1.8 \times 10^{-9} \mathrm{mbar} \cdot 1 / \mathrm{s}$. The experimedntal values obtained for five types of glue are given in Table I. The cavity is filled by immersing the wafer package into the electrolyte solution in a baker and placing it in a vacuum chamber. In this way the chamber is completely filled without any gas bubbles.

The function of the device depends on the attributes of its components. The device was characterized in two ways.

1) The mechanical behavior of different types of membranes was tested. Flat and corrugated silicon nitride membranes were made in square and circular geometry with $1 \mathrm{~mm}$ side length and $1 \mu \mathrm{m}$ thickness. The corrugation profile influences the performance of the corrugated membrane: sharp corners will lead to stress concentration [25], so a desirable shape would be a $\mathrm{V}$ groove with a rounded bottom point and rounded edges. For this, an etch process with controllable anisotropy is necessary, like reactive ion etch (RIE) (for more details about controllable dry etching by RIE see [26]).

The deflection of all membranes was measured with the use of air pressure. The sample was mounted on a holder with a pressure inlet. The pressure was measured by a pressure regulator and was increased gradually until fracture occurred. Membrane deffection was recorded by a Sloan DEKTAK 3030

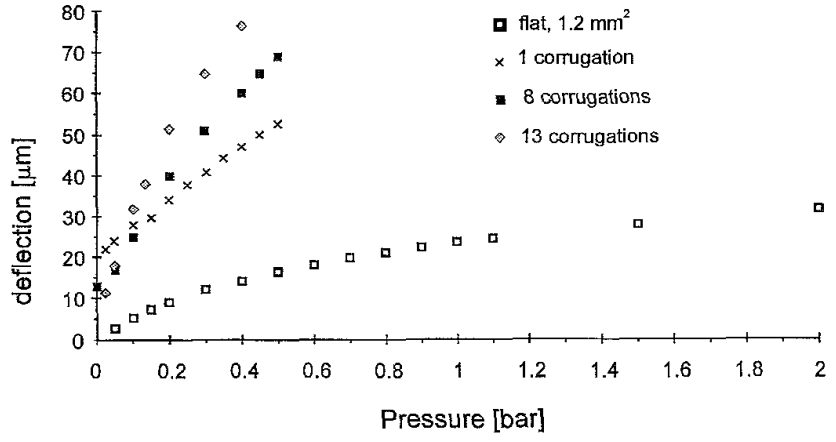

Fig. 7. Pressure-deflection measurements for different silicon nitride membranes, $1.2 \times 1.2 \mathrm{~mm}$ and $1 \mu \mathrm{m}$ thick.

profiler, which is a mechanical stylus profilometer. A stylus force of $2 \times 10^{-5} \mathrm{~N}$ was used for the flat membranes, whereas for the corrugated membranes the stylus force was $4 \times 10^{-5} \mathrm{~N}$. It was observed that the corrugated membranes showed a static deflection under zero applied pressure (see Fig. 7). This is due to the fact that there are tensile stresses in a membrane with a nonsymmetry in transferse direction (the corrugations). The occurring bending moments will result in a small deflection, as was also observed with finite-element calculations [27], [28].

A set of measured pressure-deflection curves for a flat, square membrane and for three different, circular corrugations is shown in Fig. 7: one corrugation with a depth of $15 \mu \mathrm{m}, 8$ corrugations of $11 \mu \mathrm{m}$ deep, and 13 corrugations of $9 \mu \mathrm{m}$ deep. Analytical simulations for flat membranes with initial stress $\sigma=10^{8} \mathrm{~N} / \mathrm{m}^{2}$, Young's modulus $E=3 \times 10^{11} \mathrm{~N} / \mathrm{m}^{2}$, and Poisson's ratio $v=0.3$ were carried out, and the experimental data are in good agreement with these simulations. The amount of gas produced can be calculated from the linear range of deflection/pressure "calibration curve," the volume of the cell cavity, and measurements of the deflection during oxygen pressure build up. For first measurements with oxygen pressure generated by electrolysis, flat membranes were used.

2) The performance of the electrochemical cell was characterized for the three different states. Measurements were conducted at constant current. Variation of the voltage across the electrochemical cell (Vcell) and deflection of the membrane were measured simultaneously with a $1-\mathrm{M} \Omega$ input impedance recorder. All deflections measured are in the linear range of the pressure-deflection curve, so the oxygen pressure is proportional to the deflection measured (the DEKTAK profilometer used in the measurements of Fig. 7 cannot be used here because it does not allow measurement of the deflection at one particular point on the membrane as a function of time). The deflection of the membrane was sensed by an atomic force microscope setup in order to investigate dynamic behavior. The deflection of the membrane causes displacement of the force sensor, which is detected with an optical beam deflection technique. The atomic force microscope is described in more detail elsewhere [29]. The maximum deflection measurable with the atomic force microscope is only a few micrometers. For this reason we did not measure at pressures higher than 30 mbar. For larger deflections of the membrane other techniques have to be used. 


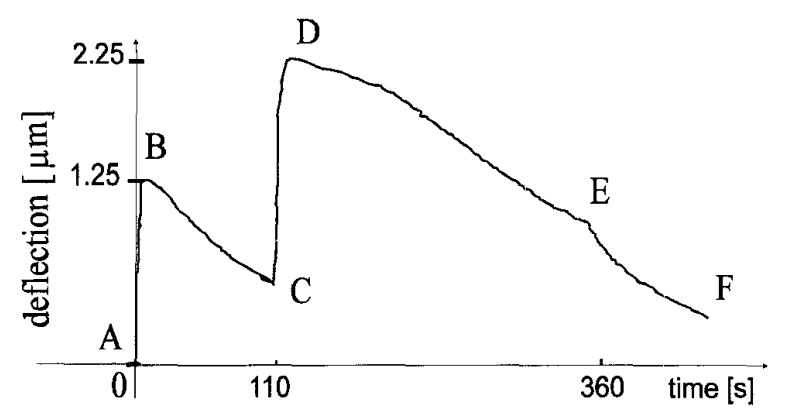

Fig. 8. The behavior of the membrane in time: the curves $A B, C D$ : the gas pressure builds up when a current of $50 \mu \mathrm{A}$ is applied; the curves $\mathrm{BC}, \mathrm{DE}$ : the electrodes are short-circuted and the pressure decreases; curve EF: the pressure drops faster when a negative current $(-50 \mu \mathrm{A})$ is applied.

\section{RESUlTS AND Discussion}

It was observed that for a positive voltage $(\leq 2 \mathrm{~V})$ and $\mathrm{a}$ current of about $1 \mathrm{~mA}$, a huge production of oxygen gas (bubbles) occurred, so that flat membranes were blown up within a few seconds. In order to study the behavior of the actuator, currents below $50 \mu \mathrm{A}$ were used to ensure slower and more controllabled gas production. The behavior of the membrane deflection in time is shown in Fig. 8: the applied current generates a gas pressure, which causes membrane deflection (curves $\mathrm{AB}, \mathrm{CD}$ ); by short-circuiting the electrodes the pressure decreases (curves $\mathrm{BC}, \mathrm{DE}$ ), and by inverting the polarity of the current $(-50 \mu \mathrm{A})$ the pressure drops faster (curve EF).

For an applied constant dc current of $2 \mu \mathrm{A}$, the voltage actoss the actuator cell increased asymptotically to a value of $1.1 \mathrm{~V}$ within a few minutes. After $20 \mathrm{~min}$, however, still no oxygen production could be observed, although the voltage was larger than the equilibrium potential of $0.89 \mathrm{~V}$ (see Section II). For this current, an $\mathrm{O}_{2}$ production rate of $5 \cdot 10^{-12} \mathrm{~mol} \mathrm{~s}^{-1}$ was expected. Assuming that the cell is absolutely gas-tight, we may explain the absence of $\mathrm{O}_{2}$ bubbles by the diffusion of $\mathrm{O}_{2}$ through the Nafion( ${ }^{\circledR}$, and its subsequent reduction at the $\mathrm{Cu}$ electrode. Values reported for the diffusion coefficient of $\mathrm{O}_{2}$ through Nafion® films range from $1 \cdot 10^{-11}$ to $2 \cdot 10^{-10} \mathrm{~m}^{2}$ $\mathrm{s}^{-1}$ [30], [31]. If the Nafion® film thickness is at least $1 \mu \mathrm{m}$, the copper electrode area is $0.8 \mathrm{~mm}^{2}$ and the maximum $\mathrm{O}_{2}$ concentration difference between both sides of the Nafion $\AA$ film is $1.03 \mathrm{~mol} \mathrm{~m}^{-3}$ (which is approximately the maximum solubility of oxygen in the solution under these conditions), we estimate an oxygen loss rate of about $8 \cdot 10^{-12} \mathrm{~mol} \mathrm{~s}^{-1}$. Since this is higher than the expected production rate, it is not surprising that we did not observe oxygen production. It should be mentioned that these are just estimates, since we do not know exactly the active area of the copper electrode nor the thickness of the Nafion ${ }^{\circledR}$ film (but the order of magnitude is correct).

For a current of $5 \mu \mathrm{A}$, the deflection of the membrane due to the generation of gas (curve $\mathrm{AB}$ ) and its reduction by short circuiting the cell (point B) are shown as a dashed line in Fig. 9(a). In addition, the variation of Vcell is shown by a continuous line. Fig. 9(b) shows the open circuit mode under the same conditions. Curve $\mathrm{AC}$ is the build up of pressure,

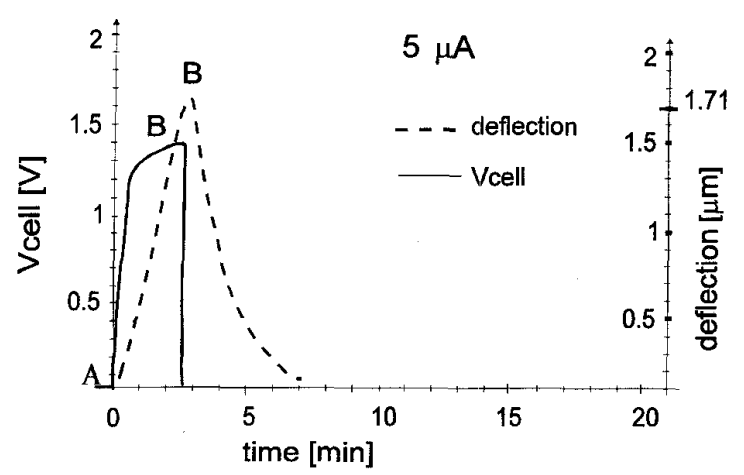

(a)

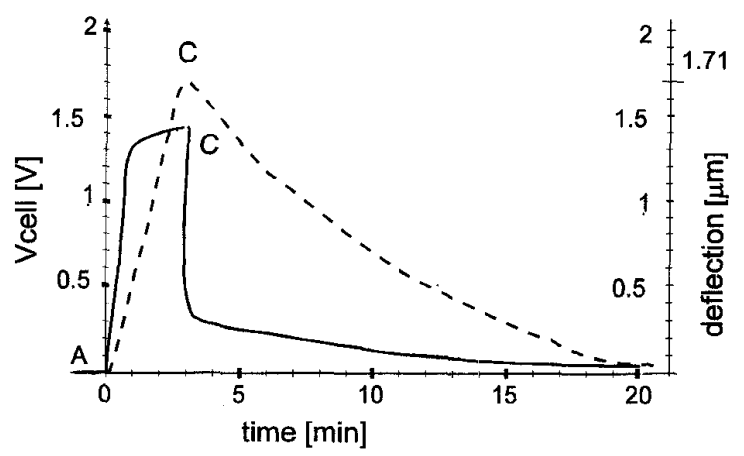

(b)

Fig. 9. The voltage across the electrochemical cell (Vcell) and the deflection of the membrane versus time. The applied constant current is $5 \mu \mathrm{A}$. In point $B$ the cell is short-circuited, and in point $C$ the circuit is opened.

and at point $C$ the circuit is opened. For a deflection of 1.25 $\mu \mathrm{m}$, the pressure obtained is 20 mbar and the build up time is $100 \mathrm{~s}$ for $5 \mu \mathrm{A}$. At points $\mathrm{B}$ and $\mathrm{C}$, the pressure is $27 \mathrm{mbar}$ for $1.71 \mu \mathrm{m}$ and the build up time is $180 \mathrm{~s}$.

When the applied current is increased to $10 \mu \mathrm{A}$, the reactions show the same general behavior but are faster. This can be seen in Fig. 10(a) and (b). As in Fig. 9, curve AB is the building up of pressure, point $\mathrm{B}$ is the pressure reduced by short-circuiting the electrodes, and point $\mathrm{C}$ in the circuit is opened. For the same deflection of $1.25 \mu \mathrm{m}$, the pressure obtained is $20 \mathrm{mbar}$, but the build up time is $42 \mathrm{~s}$ for $10 \mu \mathrm{A}$. At points B and C, pressure is $33.4 \mathrm{mbar}$ for $2 \mu \mathrm{m}$ and the time is $60 \mathrm{~s}$.

Theoretically, the oxygen production rate for a current of $5 \mu \mathrm{A}$, i.e., the situations of Fig. 9, is $13 \cdot 10^{-12} \mathrm{~mol} s^{-1}$. From the data obtained, we derive a pressure increase rate of $15 \mathrm{~Pa} \mathrm{~s} \mathrm{~s}^{-1}$. As the volume of the cell is about $1.3 \mathrm{~mm}^{3}$, the experimentally observed oxygen production rate is about $7.8 \cdot 10^{-12} \mathrm{~mol} s^{-1}$. Since the difference between this value and the theoretical one can be considered to be the oxygen removal rate by diffusion through the Nafion $\otimes$ and reaction at the copper electrode (see above), we now have a possibility to estimate the diffusion coefficient of $\mathrm{O}_{2}$ through the Nafion $\AA$ film. With the assumptions mentioned before, we arrive at a diffusion coefficient of about $0.6310^{-11} \mathrm{~m}^{2} \mathrm{~s}^{-1}$, which is within the range of the reported values. The theoretical and experimental values of the production and loss rate for oxygen 


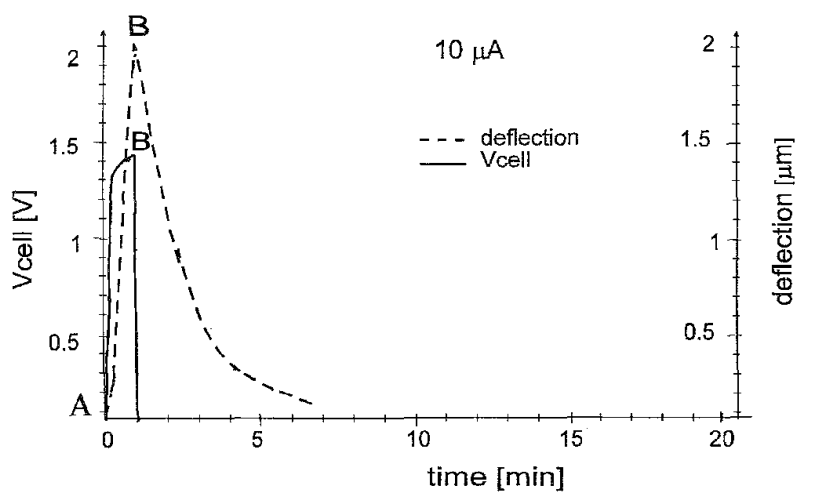

(a)

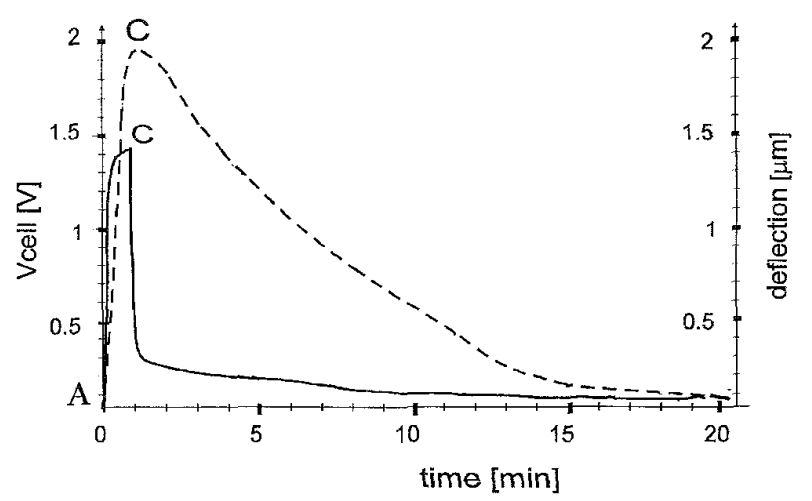

(b)

Fig. 10. The variation in time of the voltage across the electrochemical cell (Vcell) and the deflection of the membrane for an applied current of $10 \mu \mathrm{A}$. In point $B$ the cell is short-circuited and in point $C$ the circuit is opened.

TABLE II

Theoretical and Experimental Data OF OXYGEN PRODUCTTON AND LOSS RATE

\begin{tabular}{c|c|c|c}
\hline $\mathrm{I}[\mu \mathrm{A}]$ & \multicolumn{2}{|}{$\begin{array}{c}\mathrm{O}_{2} \text { production rate }[\mathrm{mol} / \mathrm{s}] \\
\text { theoretical } \\
\text { experimental }\end{array}$} & $\begin{array}{c}\mathrm{O}_{2} \text { loss rate } \\
{[\mathrm{mol} / \mathrm{s}]}\end{array}$ \\
\hline 2 & $5.2 \times 10^{-12}$ & $-\cdots$ & $>5 \times 10^{-12}$ \\
\hline 5 & $13 \times 10^{-12}$ & $7.8 \times 10^{-12}$ & $5.2 \times 10^{-12}$ \\
\hline 10 & $26 \times 10^{-12}$ & $12.3 \times 10^{-12}$ & $13.7 \times 10^{-12}$ \\
\hline
\end{tabular}

are summarized in Table II. The loss rate is calculated from the difference between theoretical and experimental data and represents what is lost while building up the pressure.

Table III shows the time constants $r$ for the decrease of deflection $d$ (i.e., oxygen pressure) as a function of time $t$, where time dependence is assumed to be of the following form:

$$
d=d_{0} \exp (-t / \tau)
$$

In the open circuit, the oxygen reduction at the copper electrode is diffusion limited, and thus the pressure decreases
TABLE III

Time Constants $\tau$ for the OXygen Gas Pressure Decay

\begin{tabular}{c|c}
\hline Figure & $\tau[\mathrm{sec}]$ \\
\hline 9 top & 96 \\
\hline 9 bottom & 348 \\
\hline 10 top & 72 \\
\hline 10 bottom & 348 \\
\hline
\end{tabular}

slowly [slow decay Figs. 9(b) and 10(b)]. In short circuit, the reduction of oxygen takes place at both electrodes, copper and platinum, and because of that the pressure drops faster than in open circuit [fast decay Figs. 9(a) and 10(a)]. The difference between the decay constants for Fig. 9(a) and Fig. 10(a) is probably due to inaccuracy in the measurements. Also, during the build up of the pressure, oxygen may be reduced at the copper electrode, which might explain the low pressures obtained experimentally.

When the applied current pulse has a duration that exceeds a certain value [10], mass transport by convection becomes important. It can be seen that the decay of the voltage curves (when the current is switched off) has a longer duration than the rise time. A reason for this might be that during the current pulse, the electrical current governs ionic migration, while this occurs by diffusion after the current is switched off.

\section{CONCLUSION}

As a general conclusion, it can be said that the performance of the electrochemical actuator presented here depends on the efficiency of gas production; this efficiency depends not only on how gas-tight the cavity can be sealed but also on how good oxygen reduction at the copper electrode can be prevented. In the current version the protection of the copper electrode is not satisfactory, and therefore further investigations and an optimization of the protection layer has to be carried out. This might require a redesign of the actuator or the choice of a different material for the permselective membrane.

Some specifications obtained with the current version of the electrochemical microactuator are: with as little as $7 \mu \mathrm{W}$ for $100 \mathrm{~s}$, a pressure of 20 mbar was obtained, which deflected a flat membrane over $1.25 \mu \mathrm{m}$.

An advantage of the electrochemical principle over thermopneumatic and other principles, which is important for its use in active microvalves, is that a once-reached membrane deflection can be maintained without energy consumption. This requires, however, that no gas losses occur, which, as said above, is the main issue in the performance of the electrochemical actuator.

\section{ACKNOWLEDGMENT}

The authors would like to thank E. Berenschot and $\mathrm{K}$. van der Werf (both from MESA Research Institute) for their technical assistance. Prof. Dr. E. L. Greve, M. Blok (AMC 
Amsterdam), and H. Yntema, and M. Hamberg for fruitful discussions.

\section{REFERENCES}

[1] P. Gravesen, J. Branebjerg, and O. S. Jensen, "Microfluidics-A review," J. Micromech. Microeng., vol. 3, pp. 168-182, 1993.

[2] F. C. M. v.d. Pol, "Micro fluid handling systems," in Micro Systems Technologies 90, 1990, pp. 799-805.

[3] M. Elwenspoek, T. S. J. Lammerink, R. Miyake, and J. H. J. Fluitman, "Towards integrated microliquid handling systems," J. Micromech. Microeng., vol. 4, pp. 227-245, 1994.

[4] H. Janocha, "Neue aktoren," in Proc. Actuator 88, Bremen, Germany, 1988 , p. 389.

[5] W. Kempe and W. Schapper, "Electrochemical actuators," in Proc. Actuator 90, Bremen, Germany, 1990, p. 162.

[6] M. W. Hamberg, C. Neagu, J. G. E. Gardeniers, D. J. Yntema, and M. Elwenspoek, "An electrochemical microactuator," in Proc. IEEE Workshop on MEMS, Amsterdam, The Netherlands, 1995, pp. 106-110.

[7] H. Janocha, "Aktoren," in Grundlagen und Anwendungen. SpringerVerlag, 1992.

[8] A. J. Bard and L. R. Faulkner, Electrochemistry Methods: Fundamentals and Applications. New York: Wiley, 1980.

[9] Instrumental Methods in Electrochemistry, Southampton electrochemistry group, Ellis Horwood series in Physical Chemistry, 1985.

[10] E. Gileadi, E. Kirowa-Eisner, and J. Penciner, Interfacial Electrochemistry-An Experimental Approach. Reading, MA: Addison-Wesley, 1975.

[11] W. H. Smyrl, Comprehensive Treatise of Electrochemistry, J. O'M Bockris, B. E. Conway, E. Yeager, and R. E. White, Eds., vol. 4, 1980.

[12] P. H. Rieger, Electrochemistry. Englewood Cliffs, NJ: Prentice-Hall, 1987.

[13] Nafion $\oplus$ is a E. I. du Pont de Nemours \& Co. Inc. registered trademark; product catalogue no. 27, 470-4.

[14] W. G. F. Grot, "Nafion $\circledast$ as a separator in electrolytic cells," presented at the Electrochem. Soc. Meet., Boston, MA, May 1986.

[15] T. Asaoka, "The water uptake and properties of perfluorinated polymer," in Extended Abstracts Electrochemical Soc. Spring Meet., 1993.

[16] C. W. M. P. Sillen, "The effect of gas bubble evolution on the energy efficiency in water electrolysis," Ph.D. dissertation, University of Eindhoven, Eindhoven, The Netherlands, 1983

[17] W. S. Wu and G. P. Rangaiah, "An experimental study of oxygen evolution and mass transfer at microelectrodes," J. Chemical Engineering of Japan, vol. 26, no. 6, pp. 620-626, 1993.

[18] D. Pletcher, S. Sotiropoulos, "A study of cathodic oxygen reduction at platinum using microelectrodes," J. Electroanal. Chem., vol. 356, pp. 109-119, 1993.

[19] H. Jerman, "The fabrication and use of micro machined corrugated silicon diaphragms," Sensors and Actuators, vol. A21-23, 1990, p. 988.

[20] M. di Giovanni, Flat and Corrugated Diaphragm Design Handbook. New York: Marcel Dekker, 1982.

[21] J. A. Voorthuyzen and P. Bergveld, "The influence of tensile forces on the deflection of circular diaphragms in pressure sensors," Sensors and Actuators 6, pp. 201-213, 1984.

[22] J. Y. Pan, P. Lin, F. Maseeh, and S. D. Senturia, "Verification of FEM analysis of load-deflection methods for measuring mechanical properties of thin films," in Tech. Dig. IEEE Solid-State Sensors Workshop, Hilton Head Island, SC, June 1990, p. 70

[23] V. L. Spiering, S. Bouwstra, J. F. Burger, and M. Elwenspoek, "Membranes fabricated with a deep single corrugation for package stress reduction and residual stress relief," J. Micromech. Microeng., vol. 3 , p. 243, 1993.

[24] P. R. Scheeper, W. Olthuis, and P. Bergveld, "The design, fabrication, and testing of corrugated silicon nitride diaphragms," J. Microelectromechanical Syst., vol. 3, no. 1, pp. 36-50, 1994.

[25] F. Pourahmadi, D. Gee, and K. Petersen, "The effect of corner radius of curvature on the mechanical strength of micromachined single-crystal silicon structures," in Dig. Tech. Papers Transducers '91, San Francisco, CA, 1991, pp. 197-200.

[26] H. Jensen, M. de Boer, R. Legtenberg, and M. Elwenspoek, "The black silicon method. A universal method for determining the parameter setting of a fluorine based reactive ion etcher in deep silicon trench etching with profile control," in Workshop Dig. MME '94, Pisa, Italy, 1994, pp. 60-64

[27] V. L. Spiering, S. Bouwstra, R. M. E. J. Spiering, and M. Elwenspoek, "On-chip decoupling zone for package-stress reduction," in Dig. Tech Papers, Transducers '91, San Francisco, CA, 1991, pp. 982-989.
[28] Y. Zhang and K. D. Wise, "Performance of non-planar silicon diaphragms under large deflections," J. Microelectromechanical Syst., vol. 3, no. 2, pp. 59-68, 1994

[29] K. O. v.d. Werf, C. A. J. Putman, B. G. de Grooth, F. B. Segerink, E. H. Schipper, N. F. van Hulst, and J. Greve, "Compact stand-alone atomic force microscope," Rev. Sci. Instrum., vol. 64, p. 2892, 1993.

[30] D. R. Lawson, L. D. Whiteley, C. R. Martin, M. N. Szentirmay, and J. I. Song, "Oxygen reduction at Nafion film-coated platinum electrodes: Transport and kinetics," J. Electrochem. Soc., vol. 135, p. 2247, 1988.

[31] Z. Ogumi, T. Kuroe, and Z. Takehara, "Gas permeation in SPE method, II. Oxygen and hydrogen permeation through Nafion," J. Electrochem. Soc., vol. 132 , p. $2601,1985$.

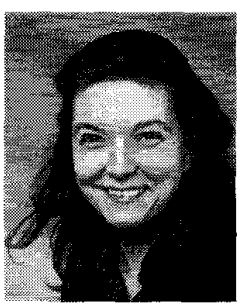

Cristina R. Neagu graduated from University of Bucharest, Faculty of Physics, Romania, in 1990 with the M.Sc. degree in applied physics.

From 1990 to 1993 she worked at the Institute of Atomic Physics, Bucharest, Romania. In 1993. she worked at MESA Institute of the University of Twente, The Netherlands, on the investigation of human immunolabelled cells by atomic force microscope. Since 1994, she has working toward the Ph.D. degree at the Transducers and Materials Science group at the same university, focusing on the design and realization of a pressure regulator based on micromachining techniques for biomedical application.

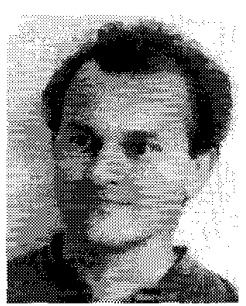

Johannes G. E. Gardeniers received the B.S. (1982) and M.S. (1985) degrees in chemistry and the Ph.D. degree in physics (1990) from the University of Nijmegen, The Netherlands.

In 1990, he joined the Department of Electrical Engineering at the University of Twente, The Netherlands, as an Assistant Professor. His research interests include materials science and microfabrication technology related to microelectromechanical systems and miniaturized chemical analysis systems.

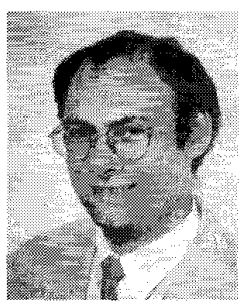

Miko Elwenspoek graduated from Freie Universitt Berlin, Germany, in 1977 (physics of liquids). He received the Ph.D. degree in 1983 (nuclear quadrupolar relaxation in liquid alloys) from the same university.

From 1983 to 1987 he did research on crystal growth of organic materials from melt and solution at University of Nijmegen, The Netherlands. Since 1987 he has been Head of the Micromechanics Department at the University of Twente. Research interests include device physics, microactuators, microsensors, microsystems, and etching mechanism and technology.

Dr. Elwenspoek is a member of the MME (Micro Mechanics Europe) Steering Committee and the Journal of Microelectromechanical Systems Steering Committee.

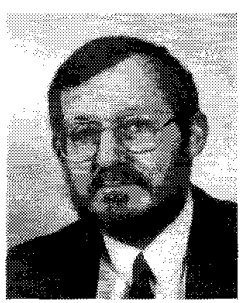

John J. Kelly received the Ph.D. degree in physical chemistry from University College Dublin in 1970. After graduation, he worked as Research Scientist at Philips Research Laboratories in Hamburg, Germany, and Eindhoven, The Netherlands. Since 1987 he has been a Professor in the Faculty of Chemistry, Utrecht University. Research interests in his group include the surface chemistry and electrochemistry of metals and semiconductors. 